\title{
RELATO DE EXPERIÊNCIA SOBRE A EXECUÇÃO DO PROJETO INFÂNCIA E TRABALHO - NOVAS ALTERNATIVAS DE ATUAÇÃO (2019), PORTO SEGURO - BA
}

\section{EXPERIENCE REPORT ON THE EXECUTION OF THE CHILDHOOD AND WORK PROJECT - NEW ALTERNATIVES OF OPERATION (2019), PORTO SEGURO - BA}

\author{
Danielle Ferreira Medeiro da Silva de Araújo \\ Pós-Graduação da Universidade Federal do Sul da Bahia (UFSB) \\ Débora Caraúna da Motta Ribeiro \\ Faculdade Castro Alves \\ Pétala Grecov Silva \\ Faculdade Nossa Senhora de Lourdes (FNSL). \\ Altemar Felberg \\ Universidade Federal do Sul da Bahia (UFSB)
}

\section{RESUMO}

O presente relato de experiência se propõe a descrever ações de intervenção social realizadas pela OSC Instituto Mãe Terra no município de Porto Seguro, Território de Identidade Costa do Descobrimento, no ano de 2019, na cidade de Porto Seguro - BA. As principais discussões do trabalho visam analisar no campo teórico e empírico a relação cambiável entre as noções de infância e trabalho a partir dos pressupostos da teoria da complexidade e epistemologias do Sul. Dentro dessa perspectiva, o Projeto Infância e Trabalho: novas alternativas de atuação foi pensado e executado com intuito de se oportunizar espaço de trocas para discussão e capacitação da rede de proteção da criança e do adolescente através de metodologias integrativas, que valorizam o ergoengajamento e as histórias de vida, com propósito de se construir novas alternativas de atuação no que tange ao fenômeno em questão. A metodologia tem enfoque qualitativo e usa como técnica a pesquisa bibliográfica, documental e o relato de experiência.

Palavras-chave: Capacitação. Ergoengajamento. Infância. Trabalho.

\section{ABSTRACT:}


This experience report proposes to describe social intervention actions carried out by OSC Instituto Mãe Terra in the city of Porto Seguro, Identity Territory Costa do Descobrimento, in 2019, in the city of Porto Seguro - BA. The main discussions of the work aim to analyze in the theoretical and empirical field the interchangeable relationship between the notions of childhood and work from the assumptions of the theory of complexity and epistemologies of the South. Within this perspective, the Childhood and Work Project: new alternatives for action was thought and executed in order to provide opportunities for exchanges for discussion and training of the child and adolescent protection network through integrative methodologies, which value ergoengagement and life stories, with the purpose of building new alternatives of action in what the phenomenon in question. The methodology has a qualitative focus and uses bibliographic, documentary research and experience reporting as a technique.

Keywords: Training. Ergoengajamento. Childhood. Job. 


\section{INTRODUÇÃO}

O Projeto Infância e Trabalho: Novas Alternativas de Atuação foi executado no município de Porto Seguro - BA, no ano de 2019, pelo Instituto Mãe Terra, e foi financiado pela Secretaria de Justiça e Desenvolvimento Social do Estado da Bahia, através do Termo de Fomento $\mathrm{n}^{\mathrm{o}}$ 016/2018, tendo como tempo de duração 8 (oito) meses. Teve como objetivo geral fomentar um espaço interdisciplinar de escuta sobre casos concretos que envolvessem situação de trabalho infanto-juvenil; e seus objetivos específicos foram analisar a complexidade dos casos de envolvessem infância e trabalho, incentivando a construção coletiva de ações interventivas; e, revisitar o estudo teórico e normativo da questão, abrindo novas alternativas de reflexão e atuação. O Projeto foi construído para alcançar 5 metas descritas a seguir:

\section{Meta o1 - Articulação político-institucional: apresentação do Projeto aos parceiros}

O ponto de partida foi a apresentação da proposta e a realização de rodas de escuta e capacitação com a rede de proteção da infância e adolescência no município de Porto Seguro - BA (Polícia Militar - 05/02/2019; CREAS - 06/02/2019; Conselho Tutelar 12/02/2019; Secretaria Municipal de Educação - 15/02/2019; OAB - 18/02/2019; Universidade Federal do Sul da Bahia - 19/02/2019; Secretaria Municipal de Saúde 21/02/2019; ONG Fábrica do Ser - 25/02/2019; Evento na Escola Modelo Luís Eduardo Magalhães - 19/03/2019; Evento na OAB - 21/03/2019; Secretaria de Assistência Social - 22/03/2019; Vara da Infância e Juventude - 28/03/2019; Secretaria Municipal de Saúde - 18/04/2019; ONG ABAMUPS - 07/05/2019; Superintendência Municipal de Promoção da Igualdade Racial - 07/05/2019; Guarda Municipal - 09/05/2019; Secretaria Municipal de Saúde Indígena - 23/05/2019; O projeto teve como foco integrar Ministério Público, Ministério Público do Trabalho, OAB, Vara da Infância, 
Universidades, Secretaria de Educação, Saúde, Cultura, Turismo, Trabalho, Polícia Civil e Militar, Conselho Municipal dos Direitos da Criança e do Adolescente, Conselho Municipal de Juventude, Comitê Municipal de Erradicação do Trabalho Infantil e instituições do terceiro setor para fortalecer a atuação intersetorial em casos de sinalizações sobre casos de trabalho infanto-juvenil.

\section{Meta 02 e 03 - Realização de 10 Oficinas/rodas de escuta e capacitação, com 4h cada, sendo duas por mês/Relatoria das Oficinas/Rodas de Escuta e Capacitação}

Para a execução do Projeto Infância e Trabalho: Novas Alternativas de Atuação foram planejadas 10 oficinas realizadas no ano de 2019 com a rede de proteção da criança e do adolescente de Porto Seguro - Bahia. Participaram das atividades propostas (com número de participantes): Policia Militar (31), Agentes de Proteção da Vara da Infância e Juventude (13), Conselho Tutelar (10), Agentes Comunitários de Saúde (27), Organizações Sociais (o9), Movimento dos Trabalhadores sem Terra- MST (19), Comunidade Cigana (25), Reserva Indígena Pataxó da Jaqueira (16), Guarda Municipal (27) e gestores das Escolas públicas municipais (34).

O que se pretendeu com a iniciativa foi uma abertura para a formação de um espaço participativo que compreendesse o sujeito integral, para além do estigma e da exclusão, um caminho que pudesse efetivamente propiciar acesso a novos conhecimentos, novas possibilidades de reconstrução da realidade e novas ações dentro dela.

A proposta buscou a construção de alternativas que pudessem estabelecer como base de atuação a proteção da criança e do adolescente, ao mesmo tempo em que promovessem as pluralidades de infâncias, buscando equalizar assim as assimetrias de 
poder advindas do processo de formação das estruturais sociais brasileiras historicamente pautadas nas desigualdades (sociais, de classe, gênero, raça, etc)ํ․

Desta forma, o Projeto como foco aumentar as chances de proteção das "crianças reais" e tornar as políticas de proteção mais efetivas, questionando a eficácia das abordagens generalistas e criminalizadoras e propondo novas alternativas de atuação pautadas em novas bases de sociabilidade.

Para tanto algumas questões implícitas dentro da abordagem tradicional do fenômeno foram refletidas no decorrer do Projeto, a saber: os pressupostos de superioridade de uma forma de vida em relação a outras/ julgamento de valor sobre formas de vida; a necessidade de tutela, não só das crianças, mas de todo sujeito que escape a certo padrão (branco, de classe média); de que sujeitos estamos falando? Todas as infâncias são protegidas respeitando sua diversidade, como indígenas e outras comunidades tradicionais (ex. ciganas), comunidades faveladas ou periféricas? Explicitar estas questões que em regra se escondem por tras da generalidade e impessoalidade das normas legais foi fundamental para se discutir sobre as assimetrias de poder que atuam na base da estrutura social brasileira, os efeitos da violência simbólica sobre as pluralidades sociais e culturais, e a necessidade de novas formas de atuação que possibilitem maior ou melhor efetividade das políticas protetivas em curso, agregando a promoção das múltiplas infâncias².

O uso da escuta ativa foi importante fator do Projeto constituído como ato social, contextual e dialógico, ou seja, uma prática complexa que imbrica dimensão individual, psicológica e social. Como ato social e dialógico, a escuta requer uma abertura para

\footnotetext{
${ }^{1}$ Ver ARAÚJO, Danielle Ferreira Medeiro da Silva de. O problema da inclusão: um olhar sobre a realidade brasileira. Revista Científica do Curso de Direito, [S.l.], n. 01, p. 147 - 164, dez. 2017. ISSN 2594-9195. Disponível em: <http://periodicos2.uesb.br/index.php/rccd/article/view/2702>. Acesso em: 23 dez. 2019. doi: https://doi.org/10.22481/rccd.voio1.2702.

${ }^{2}$ Ver ARAÚJO, Danielle F. M. S; JESUS, L. E. S; MORAIS, K. C. S. A violência Simbólica por trás da invisibilidade social: um olhar para a periferia do sul e extremo sul da Bahia. Revista Scientia. V. 6. 2018. Disponível: http://revistas.uneb.br/index.php/scientia/issue/view/Revista\%20Scientia\%20n.6 Acesso: 22 dez. 2019.
} 
reconhecer que o outro é a fonte possível de uma percepção diferenciada e tem algo a contribuir.

A necessidade de se atuar a partir desta perspectiva relacionou-se ao reconhecimento da ineficiência da abordagem tradicional, normativista e criminalizadora do trabalho infanto-juventil; o reconhecimento da pluralidade de noções de infâncias e de vivências delas; da pluralidade de sentidos atribuídos ao trabalho e de vivência dele; da importância fundamental dos contextos para uma atuação efetiva no que tange a proteção e promoção das múltiplas infâncias.

A escuta ativa tem sido base para a elaboração dos projetos sociais na área na infância e juventude no Instituto Mãe Terra. A primeira fase de escuta aconteceu durante a execução do Projeto Filhos da Terra: um despertar para a educação cidadã, que teve objetivo de construir um Diagnóstico Situacional do Trabalho Infantil no município de Porto Seguro, a partir da escuta de crianças e adolescentes de 06 (seis) a 18 (dezoito) anos incompletos, estudantes da rede pública de ensino, nos anos de 2017 e 2018, financiado pela Fundação Itaú Social, que serviu como parte da construção da justificativa para este Projeto.

Neste Projeto, a metodologia das oficinas, com duração de 4 horas, organizou-se didaticamente em três momentos: sensibilização/acolhimento, escuta de casos e capacitação. Alguns dos pressupostos para a construção da proposta foram a participação dos atores envolvidos; a flexibilidade quanto a mudanças no escopo inicial do Projeto; o caráter ergológico, ecológico e transdisciplinar que privilegiou a integração dos saberes; e as metodologias integrativas que visam a valorização do sujeito integral em processos participativos. A metodologia das oficinas de escuta configurou-se como uma proposta de ergoengajamento 3 , que privilegiou a história de vida dos atores envolvidos na rede proteção da criança e do adolescente.

\footnotetext{
${ }^{3}$ Refere-se a discussão sobre as normas e valores que renovam a atividade humana durante a relação do trabalhador com o meio em que se encontra engajado (SCHWARTZ, DUC e DURRIVE, 2010).
} 
Meta 04 - Apresentação Regular das atividades e dos resultados parciais nos encontros 100\% das atividades apresentadas mensalmente nas Reuniões com as instâncias de consulta, participação e controle social para apresentação dos casos - COMDICA, COMJUVE e COMETI

Com intuito de monitorar, avaliar e democratizar os resultados das ações o andamento das atividades foram apresentados durante as seguintes reuniões: Conselho Municipal de Juventude - 20/03/2019; reunião com conselheiros de direitos da Secretaria Municipal de Assistência Social - 04/04/2019; Conselho Municipal de Juventude (11/07/2019); Conselho Municipal dos Direitos da Criança e do Adolescente 17/07/2019). Conforme os relatórios parciais apresentados a equipe técnica do Projeto evidenciou que durante a execução do Projeto as reuniões nos referidos Conselhos não ocorreram de forma mensal, seja por falta de agendamento de encontros ou falta de quórum.

\section{Meta o5 - SEMINÁRIO FINAL DO PROJETO - Realização de Seminário de apresentação dos resultados e entrega do relatório final (100 pessoas)}

Foi realizado na Câmara Municipal de Porto Seguro, dia 23 de setembro de 2019, o Seminário Infância e Trabalho: novas alternativas de atuação, ação financiada pela Secretaria de Justiça e Desenvolvimento Social do Estado da Bahia, e executada pelo Instituto Mãe Terra, com público aproximado de 150 (cento e cinquenta pessoas).

A partir desse mapa de percurso o projeto foi desenvolvido, sendo fundamentado nos estudos das epistemologias do Sul e teoria da complexidade, pressupostos que serão discutidos no primeiro capítulo. O campo teórico encontra-se fundamentado nas noções de infância e trabalho a partir de uma perspectiva transdisciplinar que integra principalmente estudos da sociologia e antropologia da infância, psicologia e direito, que será discutido no capítulo dois. No capítulo três o foco é falar sobre a construção das normas legais e o seu digladiar com as normas sociais no espaço social. $\mathrm{O}$ capítulo quatro 
vai tratar sobre a estrutura social brasileira marcada por suas pluralidades de modos de ser e ver o mundo, em particular a relação entre as noções de infância e trabalho. Será abordado no capítulo seguinte o recorte territorial de Porto Seguro, marcado por uma trajetória histórica de diversidade cultural e social, espaço social em que o projeto se desenvolveu. No capítulo seis será apresentado os apontamentos finais do texto.

\section{INFÂNCIA E TRABALHO: A TEORIA DA COMPLEXIDADE COMO PRESSUPOSTO EPISTEMOLÓGICO}

A razão do século XVIII aparece não só como força emancipadora universal, mas também como princípio justificando a subjugação operada por uma economia, uma sociedade, uma civilização sobre as outras (MORIN, 2008). Para Dussel (2005), torna-se necessário a superação da razão emancipadora como "razão libertadora", descortinandoa quando se descobre o "eurocentrismo" da razão ilustrada, quando se define a "falácia desenvolvimentista" do processo de modernização hegemônico.

Por outro lado, o conhecimento complexo visa religar saberes, reatar articulações destruídas pelos cortes disciplinares, categorias cognitivas e tipos de conhecimento, tende para a multidimensionalidade que busca respeitar as diferentes dimensões sobre um fenômeno estudado (MORIN, 2000).

A partir da teoria da complexidade, reconheço as incertezas, irregularidades e as diversas dimensões conectivas que envolvem as noções de infância e trabalho no espaço social estudado, busco agregar ao conhecimento posto por outros valores presentes na pluralidade da sociedade, interpretando-os de forma dialógica e reflexiva, a partir de uma perspectiva integradora, ecológica e não excludente.

Trata-se de criticar os postulados universalizantes sobre a infância e adolescência que ocultem no campo das estruturas sociais as categorias de raça, gênero, localidade e classe que vão delinear a construção de diferentes sentidos para a relação entre as noções que envolvem os sujeitos e a sua ligação com o universo do trabalho. Refletindo e 
propondo novas alternativas de atuação para que as normas legais possam ser efetivadas de forma a agregar e valorizar a promoção das múltiplas infâncias nos contextos em que estão inseridas (ARAÚJO, 2019).

\section{A INFÂNCIA E O TRABALHO COMO CATEGORIA SOCIAL4:}

No âmbito teórico, o Projeto considera a infância e adolescência como categoria social5. A infância é considerada como um componente social, e não se restringe a uma concepção normativa ou na compreensão etária relativa a fases biológicas (SIROTA, 2001; MONTANDON, 2001). Tanto o desenvolvimento físico, quanto a transformação social da criança em adulto, não acontecem de forma homogênea para todos os indivíduos que se encontram numa determinada idade. As pluralidades de infâncias são reflexo das relações sociais concretas e as diferenças entre crianças não podem ser negadas (CRUZ e ASSUNÇÃO, 2008).

A noção de trabalho também se insere no âmbito da construção social e se apresenta como elemento de luta simbólica ${ }^{6}$ no espaço social7 brasileiro, e aparece historicamente como mais um instrumento de hierarquização e distanciamento social entre diferentes grupos sociais.

Nesse caso, o trabalho como estratégia de formação dos filhos, pode vir a basear-se na construção de sociabilidade e pertencimento (CRUZ e ASSUNÇÃO, 2008). Os valores que perpassam o processo de sociabilização fundamentam-se nas estruturas sociais em que os distintos grupos se estabelecem (SOUZA, 2009). Dessa forma, a articulação entre

\footnotetext{
${ }^{4}$ Íntegra do texto ver ARAÚJO, Danielle F. M. S; FELBERG, Altemar. Pluralidades e subjetividades na relação infância e trabalho: um olhar sobre a perspectiva indígena Pataxó. Anais $43^{\text {a }}$ Encontro Anual da ANPOCS. 2019. Disponível: https://anpocs.com/index.php/encontros/papers/43-encontro-anual-daanpocs/st-11/st16-8 Acesso em: 23 dez. 2019.

$5 \mathrm{O}$ uso do termo infância neste relatório inclui no processo analítico crianças e adolescentes.

${ }^{6} \mathrm{O}$ poder simbólico é entendido aquele capaz de confirmar ou transformar a visão de mundo pela enunciação, e que pelo efeito de mobilização se exerce de forma arbitrária sem que haja por parte dos que lhe são sujeitos o seu reconhecimento (BORDIEU, 2009).

7A estrutura do espaço social se manifesta sob a forma de oposições espaciais, sendo assim, o espaço habitado funciona como uma simbolização espontânea do espaço social (BOURDIEU, 2009).
} 
as noções de infância e trabalho deve ser analisada como uma questão social, determinada pelos mecanismos de reprodução das estruturas de classe (ALVES-MAZZOTI, 2002).

Diante da irregularidade e complexidade que envolve o estudo do fenômeno, a proposta de uma compreensão reflexiva e transdisciplinar tendem a ampliar os olhares sobre as diferentes interações no espaço social e atrair para o campo teórico novas interpretações que abarquem os múltiplos sentidos que envolvem as noções de infância e trabalho, propiciando, também, novas alternativas de atuação no campo em questão (ARAÚJO, 2019).

Assim, o que se pretende neste trabalho é demonstrar no campo teórico ${ }^{8}$ e empírico 9 a relação cambiável entre as duas noções envolvidas no fenômeno do trabalho infantojuvenil com intuito de se fortalecer e ampliar as ações protetivas para que crianças e adolescentes possam vivenciar seus modos de vida de forma livre e igualitária.

\section{O TRABALHO INFANTO-JUVENIL NAS NORMAS LEGAIS}

Quando se trata de trabalho infanto-juvenil enquanto violação de direitos, novos paradigmas foram firmados a partir da criação do Fundo das Nações Unidas de Socorro à Infância (UNICEF) em fins de 1946, e com atuação permanente a partir de 1953. Também pode-se citar a Declaração Universal dos Direitos da Criança, formalizado pela Organização das Nações Unidas, em 1959. No Brasil, os anos de 1980 contaram com o retorno ao Estado Democrático de Direito, a nova Carta Constitucional, movimentos sociais envolvendo as próprias crianças como o Movimento Nacional de Meninos e

\footnotetext{
${ }^{8}$ A temática foi tratada da dissertação de mestrado e tem sido objeto de estudo de doutoramento da autora Danielle de Araújo no Programa de Pós-Graduação em Estado e Sociedade na Universidade Federal do Sul da Bahia. Disponível em: https://sig.ufsb.edu.br/sigaa/verArquivo?idArquivo=409168\&key=a1b5572e2a98020aff93f212e381b881 Acesso: 20 ago. 2020.

9 Desde 2017 a Organização da Sociedade Civil, Instituto Mãe Terra, desenvolve projetos sociais na área de Infância e Juventude, com foco na temática do trabalho infantil. Em 2017 e 2018 foi realizado o Projeto Filhos da Terra: um despertar para a educação cidadã - Etapa 1 e 2, com crianças e adolescentes de 06 a 18 anos, com objetivo de se construir um Diagnóstico Situacional do Trabalho Infantil na cidade de Porto Seguro, BA.
} 
Meninas de Rua, em 1985, e medidas voltadas à infância, como a criação do SOS Criança, em 1987. Em 1989 a ONU reafirma a internacionalização da discussão através da Doutrina da Proteção Integral para a Infância (CARVALHO e MOURA, 2007).

Mesmo diante de normas universalizantes, os fenômenos ainda se mantêm, e pode ser analisado sobre diferentes prismas. Quando o olhar se direciona para a América Latina pode-se dizer que os grupos indígenas, afrodescendentes e populações rurais têm as suas cosmovisões ocultadas e criminalizadas pelos postulados de uma visão única que racionaliza a vida, que separa ao invés de integrar. Dussel (2005) aponta para a existência de uma ontologia relacional, vinculada a noções de espaço-tempo, que permite aos diferentes grupos sociais elegerem os sentidos que dão a sua própria existência.

Seria possível então se pensar em normas que tenham o caráter universalizante protetivo, como as normas de direitos humanos, mas que pressuponham também o respeito aos diferentes valores existentes? Ao falar destes, Santos (1997) assevera que o sentido de dignidade humana deve se organizar como uma constelação de sentidos locais. Assim, os mesmos deveriam ser reconceitualizados como multiculturais, a partir de uma relação equilibrada entre a competência global e a legitimidade local (SANTOS, 1997).

Em âmbito interno, a partir da promulgação da Constituição de 1988, estabeleceu-se a Doutrina da Proteção Integral, e foi prevista a idade mínima de 14 (quatorze) anos para a entrada no mercado de trabalho, sendo permitido a partir dos 12 (doze) anos, em regime de aprendizagem, permanecendo a proibição do trabalho noturno, perigoso ou insalubre para menores de 18 (dezoito) anos. O Estatuto da Criança e do Adolescente (Lei 8.069/1990) teve como papel reforçar a ideia de proteção integral. Com a Emenda Constitucional n.20, 15/12/1998, a idade mínima para o trabalho fora elevada para os 16 (dezesseis) anos, permitida a aprendizagem a partir dos 14 (quatorze) anos.

De acordo com Vilani (2010), o caráter histórico-cultural da temática revela movimentos dialéticos complexos, e identifica que em algumas famílias, diante da impossibilidade de se desempenhar os papéis estabelecidos pelo modelo dominante, acabavam por constituir alternativas para a composição familiar como a aceitação do trabalho infantil para a provisão econômica da família. 
Para além dessa perspectiva, apresentamos como pressuposto do trabalho que tanto a noção de infância como a de trabalho estão inseridas em um contexto social próprio que se baseia em uma estrutura social desigual, mas não apenas, também se vinculam a princípios de visão sobre a realidade.

\section{A ESTRUTURA SOCIAL BRASILEIRA E AS MUDANÇAS NA VALORAÇÃO DA RELAÇÃO ENTRE INFÂNCIA E TRABALHO}

Para melhor compreender a infância e adolescência marcada pelo trabalho dentro do contexto histórico-social brasileiro, o presente relatório fundamenta as suas reflexões a partir dos conceitos propostos pela teoria estruturalista-construtivista de Pierre Bourdieu. A concepção estruturalista aponta a existência de estruturas objetivas no mundo social que se impõem independente da consciência e da vontade dos agentes, e são capazes de coagir suas práticas e representações. Por outro lado, a concepção construtivista refere-se aos esquemas de percepção, pensamento e ação que exprimem o estado das relações de poder simbólico (BOURDIEU, 2009).

A estrutura subjetiva deste espaço expressa-se através do conceito de habitus, produto de uma aquisição histórica que permite a apropriação do adquirido histórico, recuperando a dimensão simbólica e individual dos fenômenos sociais.

A dupla estruturação do espaço social concorre para produzir um consenso mínimo no mundo. Todavia, os objetos deste universo são percebidos e interpretados de formas diversas, pois sempre comportam uma parcela de indeterminação, fluidez e elasticidade semântica (BOURDIEU, 2004). Assim, este elemento de incerteza ocasiona que uma mesma palavra possa englobar práticas distintas, abrindo portas para a pluralidade de cosmovisões, e concomitantemente, torna-se também base para as lutas simbólicas, pelo poder de produzir e impor a visão de mundo legítima (BOURDIEU, 2004).

No caso deste relato, as noções de infância e trabalho são apresentadas em um contexto de dupla concepção: tanto dentro de uma visão legítima, que prescreve um 
significado normativo, válido de forma universal e impessoal; assim como, a partir da construção de normas sociais presentes no espaço social onde estes elementos são ressignificados de acordo com os modos de vida que os distintos grupos adquirem e reproduzem no decorrer no tempo.

As lutas simbólicas entre estas distintas concepções são marcadas pela hegemonia de uma visão normativa, institucional e acadêmica, em prol da erradicação do trabalho infantil, em contraposição a deslegitimação de quaisquer outros pontos de vista que se manifeste no espaço social, ocasionando conflitos que envolvem relações de poder. Estas relações de força operam de forma multidimensional em um tempo dado e em uma sociedade determinada, e se perfazem em rituais políticos de poder, produzindo, assim, relações desiguais e assimétricas (DREYFUS e RABINOW, 2001).

Desnaturalizar os conceitos de infância e trabalho a partir da compreensão das pluralidades significa descortinar as relações de poder que envolvem estas noções e compreender os múltiplos processos de interações sociais em que crianças e adolescentes estão inseridos no meio em que vivem. Significa compreender os processos de sociabilização a partir de contextos múltiplos, reconhecendo a influencia das desigualdades históricas, mas também as riquezas dos saberes advindo de uma trajetória biográfica coletiva (ARAÚJO, 2019).

\section{COMPREENDENDO AS PLURALIDADES DE INFÂNCIAS NO CONTEXTO SOCIOCULTURAL DE PORTO SEGURO - BA}

O presente relato de experiência se propõe a descrever ações de intervenção social realizadas pela OSC Instituto Mãe Terra no município de Porto Seguro, Território de Identidade Costa do Descobrimento, região dividida territorialmente em áreas rural, urbana e indígena. A possibilidade de se observar as pluralidades de infâncias reveladas pela diversidade dos grupos sociais integrantes do território, como negros, indígenas, ciganos, assentados do Movimento dos Trabalhadores Rurais Sem Terra (MST), entre 
outros, oportunizou no campo empírico a compreensão da complexidade de se atuar com a temática do trabalho infanto-juvenil, tendo em vista as múltiplas infâncias que compõem o espaço social. Durante a execução dos projetos Filhos da Terra e Infância e Trabalho, percebemos a pluralidade cultural do município de Porto Seguro e as diversas concepções sobre infância e trabalho.

6.1. Justificativa e bases teóricas do Projeto Infância e Trabalho

A justificativa do Projeto "Infância e Trabalho: Novas Alternativas de Atuação"1o fundamenta-se nas rodas de escuta com a Rede de Proteção da Infância e Adolescência de Porto Seguro durante o período de atividades preparatórias do Projeto Filhos da Terra um despertar para a educação cidadã (2017/2018)11. Os encontros com a rede aconteceram entre os meses de abril a junho de 2018 e revelaram problemáticas, tais como: a saída das famílias para a colheita do café, acompanhadas de suas crianças e adolescentes, a comercialização de artesanatos pelas crianças indígenas, o trabalho informal em feiras e oficinas, e o aliciamento de crianças e adolescentes pelo tráfico de drogas na periferia da cidade, entre outras questões.

${ }^{10}$ Dados preliminares do Projeto foram publicados em ARAÚJO, Danielle F. M. da Silva de; FELBERG, Altemar. Pluralidades e Subjetividades na Relação Infância e Trabalho: um olhar sobre a perspectiva indígena pataxó. Anais do $43^{\circ}$ Encontro Anual da ANPOCS, de 21 a 25 de outubro de 2019, em Caxambu-MG. ISSN 2177-3092. $<$ https://anpocs.com/index.php/encontros/papers/43-encontro-anual-da-anpocs/st-11/st16-8/11727pluralidades-e-subjetividades-na-relacao-infancia-e-trabalho-um-olhar-sobre-a-perspectiva-indigenapataxo

${ }^{11} \mathrm{Em} 2017$ iniciou-se um trabalho de complementação do diagnóstico do trabalho infantil no município de Porto Seguro - BA para a faixa etária de 6 (seis) a 12 (doze) anos incompletos, proposto pelo COMDICA Conselho Municipal dos Direitos da Criança e do Adolescente, e executado pelo Instituto Mãe Terra - IMT, por meio do Projeto Filhos da Terra, e apoiado pela Fundação Itaú Social. Em linhas gerais, o Projeto visou complementar o Diagnóstico Situacional do Trabalho Infantil do Município de Porto Seguro com o levantamento primário das formas de labor prevalentes no universo de 107 (cento e sete) escolas da rede pública de ensino, utilizando-se uma metodologia diagnóstica interativa - contação de história, vernissage e baile do futuro. No segundo momento, em 2018, com foco em adolescentes de 12 a 18 anos, o olhar para o Projeto foi direcionado para a compreensão da complexidade do fenômeno no espaço social, sendo evidenciado sobre as múltiplas concepções existentes sobre as noções de trabalho e infância. 
Com o objetivo de fomentar um espaço interdisciplinar de escuta sobre casos concretos que envolvessem a situação de trabalho infantil na cidade foi elaborado o Projeto Infância e Trabalho: Novas Alternativas de Atuação, que foi aceito para financiamento pelo Conselho Estadual dos Direitos da Criança e do Adolescente da Bahia. A equipe técnica é formada por uma coordenação executiva (advogada e doutoranda na temática do trabalho infantil), psicóloga e assistente técnica.

O pressuposto pedagógico trabalha a perspectiva progressista libertadora cunhada por Paulo Freire, que privilegia o diálogo como método de ensino, "no processo da fala e da escuta, a disciplina do silêncio a ser assumida com rigor e a seu tempo pelos sujeitos que falam e escutam é um sine qua da comunicação dialógica” (FREIRE, 1996, p. 114). Nessa perspectiva, a equipe do Projeto aprendeu antes de tudo a escutar, a silenciar-se, para ouvir e entender a leitura de mundo dos participantes da oficina, e entender quais os valores e normas sociais constroem a visão sobre o trabalho e a infância para os diferentes grupos socias do território.

Visando uma aprendizagem significativa, numa concepção construtivista ${ }^{12}$, de construção pessoal de significado sobre o objeto de aprendizagem, segundo Zabala (1998), ao planejar a sequência didática algumas perguntas podem ser feitas com o intuito de se verificar se segue a sequência e se o conteúdo permitem determinar os conhecimentos prévios que o educando tem em relação aos novos conteúdos de aprendizagem; se os conteúdos são propostos de forma que seja significativo e funcional; se representam um desafio alcançável.

Neste sentido, o grande desafio do projeto foi desenvolver de forma participativa e interativa uma metodologia que pudesse agregar novos aprendizados enquanto, 
concomitantemente, valorizasse os conhecimentos prévios dos participantes, na perspectiva de se compreender a "leitura de mundo" (FREIRE, 2007) de cada grupo.

A concepção interacionista do Projeto foi o que permitiu a equipe técnica superar os valores advindos do meio sócio-histórico pessoal e adentrar outros universos de sentidos com o objetivo de aprender e trocar conhecimentos, apoiados na perspectiva de se agregar às competências existentes em cada grupo, inclusive ao da equipe do Instituto Mãe Terra, uma contribuição para o desenvolvimento social destes espaços.

\subsection{Metodologia do Projeto Infância e Trabalho}

A metodologia das oficinas com duração de 4 horas organizou-se didaticamente em três momentos: sensibilização/ acolhimento, escuta de casos e capacitação, objetivando analisar a complexidade dos casos que envolviam infância e trabalho, incentivando a construção coletiva de ações interventivas. Para atingir tal objetivo, seguiu-se a descrição didática metodológica das oficinas. Cada experiência pedagógica seguiu um caminho distinto, suscitado pelas vivências dos participantes, sempre únicas.

Nas oficinas do Projeto Infância e Trabalho tínhamos como objetivo a dialética desses saberes para que através do diálogo interno os atores da rede de proteção da criança e do adolescente pudessem refletir sobre a sua trajetória de vida pessoal, identificando a existência de pessoas que exerceram influência na sua escolha profissional e o modo como este incentivo e/ou informação era ofertado. (se no caminho profissional houve pessoas que fizeram a diferença na sua trajetória pessoal de modo positivo?) Essas pessoas lhes falaram palavras de incentivo ou lhe deram informações sobre o próximo passo? Estas reflexões abriam portas para falarmos sobre a da importância de se atuar de forma positiva junto à na rede de referência da criança e do adolescente através do debate entre as normas antecedentes e possíveis renormalizações, possibilitando assim a construção de um novo universo de escolhas e vidas possíveis.

\subsubsection{Momento de sensibilização}


O momento de sensibilização/acolhimento consistia na qualificação do indivíduo sobre si mesmo, o que para ergologia refere-se aos saberes investidos. Compreendido como os saberes investidos no corpo - si, “[...] 'corpo-si', árbitro no mais íntimo da atividade, [...] que não é um 'sujeito' delimitado, definido, mas uma entidade enigmática que resiste às tentativas de ser objetivado" (SCHWARTZ, DUC e DURRIVE, 2010e, p. 196).

Ao se apresentarem, era pedido que atribuíssem uma qualidade da sua personalidade que começasse com a primeira letra do seu nome. A escolha por esta forma de apresentação tinha por objetivo resgatar a identidade subjetiva do indivíduo, já que os nomes e sobrenomes, por não possuírem sentido próprio, necessitam da atribuição de um significado a partir do processo de autopercepção do sujeito. A escolha por esta forma de apresentação tinha por objetivo estimular o diálogo interno para melhor compreensão e ressingularizações de qualidade pessoais como recurso para uso de si no trabalho.

Esta noção de pertença é entendida enquanto produto da relação entre o individual e o social, portanto, implica o próprio eu e o outro nas suas várias representações, como a família, os pares, as instituições e a comunidade (LACAN, 2003). A ideia central da atividade foi o fortalecimento das qualidades dos participantes como importante ferramenta motivacional e transformativa em suas trajetórias, pessoal, social e profissional.

Algumas das principais experiências deste momento foram: um dos participantes se atribuiu a qualidade de "rebelde", mas ficou pensativo se era qualidade ou defeito... muito foi discutido sobre o papel da rebeldia para a mudança do status quo na sociedade. Ao final da oficina o mesmo reconheceu que a característica era utilizada por ele para enfrentar situações de injustiças, ${ }^{13}$; em outra oficina, uma participante de nome Natalina se envergonhou ao dizer seu nome e se apresentou como os outros costumavam chamála, Nati. Após a análise etimológica da palavra e de suas características, realizada com

\footnotetext{
${ }^{13}$ Relato compartilhado na oficina realizada com Conselheiros Tutelares.
} 
auxílio da psicóloga da equipe técnica, a participante disse se sentir mais segura e orgulhosa a utilizar seu nome ${ }^{14}$. Nestes momentos, os participantes eram incentivados a buscarem em suas qualidades, recursos intrínsecos para qualificar a sua atuação profissional, independente dos desafios profissionais, ampliando, assim, a influência positiva de forma direta ou indireta sobre as crianças e famílias.

Em seguida eram apresentados alguns dados que foram coletados durante a execução do Projeto Filhos da Terra - Diagnóstico Situacional do Trabalho Infantil na cidade de Porto Seguro - BA. O foco da atividade foi expor as dificuldades trazidas pelas crianças e adolescentes para realização do sonho profissional, citando as principais dificuldades e os sonhos dos mesmos. Dificuldades: falta de oportunidades; falta de condições econômicas; dificuldades de transporte; medo de não conseguir/falta de apoio da família; dificuldades nos estudos. Sonhos: cursar o ensino superior em diferentes áreas (humanas, exatas, carreiras policiais e militares, área de saúde, etc); auxiliar financeiramente a família; ser jogador/a de futebol etc.

A partir da visualização desses dados, os participantes foram convidados a rememorar seu caminho pessoal para a conquista profissional, identificando quais dificuldades foram semelhantes às enfrentadas pelos adolescentes. Assim, foi perguntado: Como os seus sonhos influenciaram você e quais as realidades encontradas/enfrentadas para alcançá-los? Como você chegou até aqui? E como você pensa que poderia auxiliar para que as crianças e adolescentes possam alcançar os seus sonhos?

As respostas apontaram que para além da realidade objetiva de falta de oportunidades e condição financeira, a atitude familiar e do grupo em relação ao êxito escolar fizeram a diferença na trajetória profissional dos participantes: "Meu pai era semianalfabeto. Tive que me esforçar muito nos estudos. Não perdia aula, eu tinha que estar ali para meu professor me explicar, não podia cobrar isso dos meus pais. O pouco conhecimento que eu tinha para minha mãe era muito. Às $16 \mathrm{~h}$ da tarde ela sempre fazia

\footnotetext{
14 Relato compartilhado na oficina realizada com Agentes Comunitários de Saúde.
} 
um misto quente para mim enquanto eu fazia a atividade, isso é muito marcante." 15. "Vou começar hoje na UFSB, não era o curso que eu queria, mas minha colega do projeto entrou e falou para eu entrar também..." 16.

Em especial, a trajetória de um dos participantes demonstrou que ser uma referência positiva está relacionado a aspectos relacionais afetivos com a disponibilidade para escuta e o diálogo: "A universidade era um sonho, a faculdade mais próxima era a UESC, longe de casa, acabamos nos limitando, o ensino médio para mim foi o topo. Hoje é diferente. A falta de oportunidade antes nos limitava. A educação antigamente era para poucos. Sou o funcionário mais antigo da escola que atende 6.825 alunos. Recebemos todos os adolescentes da periferia. Eu resolvo as coisas que o diretor não resolve, eu resolvo pelo fato de ouvir, dialogar, conversar, se portar como amigo, não reprimir, trazer esse aluno, nortear eles, porque a família não tem estrutura. Se expulsar esse menino da escola ele vai para onde? Teve um caso de um aluno muito problemático que foi transferido de uma escola municipal para a estadual, ele apanhava muito da mãe. A questão é que ele sofria bulling e era muito violento, mas eu conversava muito com ele para ele não desistir da escola, hoje o menino está no IFBA, trabalhando, tudo certinho, imagina se eu tivesse desistido dele?" 17.

Outros relatos foram: "Tive dificuldades econômicas e de localização. Meu pai queria que eu virasse dentista. Eu morava numa fazenda de cacau ${ }^{18}$, o dono era farmacêutico da marinha, ele disse que para ser dentista eu tinha que fazer odontologia. Quando dava a cheia, o rio Jequitinhonha subia e alagava tudo e eu que queria saber o

\footnotetext{
${ }^{15}$ Relato compartilhado na oficina realizada com Conselheiros Tutelares.

${ }_{16}$ Relato compartilhado na oficina realizada com Organizações Sociais.

17 Relato compartilhado na oficina realizada com os Agentes de Proteção da Vara da Infância de Porto Seguro.

18 "Na região cacaueira, o menino fez 10 anos já está trabalhando para suprir o dinheiro. Muitos pais que moram aqui vieram de lá, já vem com essa cultura. Essa tradição. Se o filho não ajudar vai passar necessidade em casa. Talvez se isso for um pouco desconstruído, para que nossos filhos não vivenciem o que nós vivenciamos. Eu parei de estudar por um período, porque achava a escola desinteressante. Eu dou aula na região cacaueira e vejo a mesma infância”. Essa fala foi um relato compartilhado na oficina com Organizações Sociais sobre a formação do bairro periférico Frei Calixto. O bairro foi fundado em 1990 por moradores que em sua maioria migraram da região cacaueira em virtude da crise do cacau. (ARAÚJO, 2004)
} 
porquê, aí o dono da fazenda falou que esse impacto ambiental era estudado pelo Engenheiro Florestal, com 9 ou 10 anos surgiu em mim a vontade de ser engenheiro ambiental..." 19.

\subsubsection{Momento de escuta de casos}

Enquanto a escuta de si aborda a reflexão dos valores, conhecimentos e habilidades que já se tem, reconhecendo os próprios sentimentos em relação a fala do outro; a escuta do outro visa a integração de outros olhares, abrindo espaço para uma ação coletiva conectada com as necessidades locais. A abertura para uma escuta profunda, compreende a integridade do ser e possibilita o respeito aos hábitos e culturas diferentes. Cria espaço para coprodução dos significados a partir da interação do mundo de si, do outro, do grupo e do contexto. A multidimensionalidade da escuta baseia-se no reconhecimento da parcialidade de um ponto de vista, a partir do qual vejo e construo a realidade (MOURA, 2015).

A escuta de casos foi espontânea e direcionada por outras perguntas a respeito da infância e da trajetória de vida profissional dos participantes, tais como: Com quantos anos você começou a trabalhar? Essa experiência foi positiva ou negativa? Algumas das principais experiências deste momento podem ser acrescidas aqui.

Alguns relatos foram: "eu usava o dinheiro para comprar material escolar, comprar picolé, ou ajudar numa conta ou outra, minha mãe e meu pai me ajudaram nos estudos, eu era ajudante de pedreiro no contra turno. Hoje minha mãe fez o ensino médio e é pedagoga. Não é a falta de oportunidade, é falta de alguém para incentivar. Quando eu terminei o ensino médio estava trabalhando no caixa de mercado, um professor de matemática meu passou e perguntou por que eu estava ali, eu disse que não tinha passado no Enem, ele disse para eu fazer de novo porque sou inteligente, e hoje eu estou aqui” ${ }^{20}$.

\footnotetext{
19 Relato compartilhado na oficina com Agentes de Proteção da Vara da Infância e Juventude Porto Seguro.

${ }^{20}$ Relato compartilhado na oficina realizada com Policiais Militares.
} 
Outro participante contou: "a experiência foi positiva. Trabalhei antes dos 14 anos. Aprendi a ter disciplina, valorizar o dinheiro e me ajudou durante a vida. Eu trabalhava na feira, tinha um empresário do ramo de gás que sempre me incentivava, ele foi referência para mim, como um pai. Quando me tornei funcionário público, eu o atendi, ele ficou muito feliz em me ver ali e me deu parabéns, disse para eu continuar” 21

A respeito da pergunta "Porque que os adolescentes trabalham?", as respostas apontaram questões econômicas: "Por necessidade..."; "Famílias que só tem mãe, a mãe precisa botar o filho para ajudar. ” 22. De padrão de consumo: “Às vezes tem um padrão e o pai não pode manter, ele quer comprar suas coisas." 23. E valorativas: "Você tem que trabalhar para ser alguém na vida para não ser marginal” 24.

Fez também parte da metodologia a interação com o poder das palavras a partir da “convicção de que as palavras produzem sentido, criam realidades e, às vezes, funcionam como potentes mecanismos de subjetivação" (BONDÍA, 2002, p.21). Para aplicação desta concepção, foi apresentado o conceito de "bendizer", ou o mesmo que "palavra bem-dita"; "abençoar; fazer com que algo se torne próspero, abençoado. Enaltecer; falar coisas boas; abençoar algo ou alguém; dar a bênção.” E “maldizer”, ou o mesmo que "palavra mal-dita”; "Maledicência; fala maldosa; ação de quem difama. Difamar; falar mal de alguém; atacar a boa reputação (FERREIRA, s.d). Algumas das principais experiências deste momento podem ser acrescidas aqui.

Sobre "bendizer" os sonhos profissionais dos filhos, uma participante disse: “A planta que deve ser regada a família mesmo mata o sonho, pela questão financeira. Quando os meninos fazem 18 anos, têm que trabalhar. E também a maioria da família não estudou e está vivendo. Vai virando uma bola de neve...”. Relato que corrobora com o dito por outro participante a respeito do acesso ao Ensino Superior "para as famílias terminou o ensino médio "acabou”, é como uma tradição... se você tem pais que não ligam para

\footnotetext{
${ }^{21}$ Relato compartilhado na oficina realizada com Policiais Militares.

22 Relato compartilhado na oficina realizada com Organizações Sociais.

23 Relato compartilhado na oficina realizada com Organizações Sociais.

24 Relato compartilha na oficina realizada com a Guarda Municipal.
} 
educação dos seus filhos, esses filhos serão pais que não ligam para educação dos seus filhos, isso vai se perpetuando, cria uma cultura" 25.

Este convite de imersão em si mesmo possibilitou ao outro educar-se a partir do compartilhamento dos saberes que tem sobre si, o aprofundamento do que "si" é para promoção da empatia. Ou seja, "ninguém jamais poderá encerrá-lo em uma moldura, por mais sedutora que ela seja" (SCHWARTZ, DUC e DURRIVE, 2010e, p. 198). Neste sentido podemos dizer que para uma atuação ergológica da rede de proteção da criança e do adolescente torna-se preciso abandonar o emolduramento que encerra o sujeito na perspectiva "estou fazendo o que está escrito" para promover neste ator o resgate de saberes investidos e o reconhecimento de competências sobre si mesmo.

De acordo com Schwartz (2000) o "uso de si” é manifestação do "si" na relação com o trabalho, para tanto, tornar consciente a escolha de "bem dizer" ou "mal dizer" proporciona ao ator envolvido na rede de referência da criança e do adolescente a escolha de exercer a atividade laboral tendo como possibilidade escolher por si mesmo criar relações respeitosas dentro da dramática do uso de si. Segundo Schwartz (1988, P.104) "uma dramatiqueé, portanto, o lugar de uma verdadeira micro-história, essencialmente inaparente na qual cada um se vê na obrigação de se escolher ou escolher orientar sua atividade de tal ou tal modo".

A importância deste saber investido, das histórias de vida de cada um dos participantes foi importante para se transpor as dificuldades de implementação fria das normas e das leis que direcionam o comportamento profissional dos mesmos. A sensibilização para o cuidado e valorização dos valores de cada ator foi fundamental para o segundo momento de capacitação, pois agregou sentido ao saber constituído.

\subsubsection{Momento de capacitação}

\footnotetext{
${ }^{25}$ Relato compartilhado na reunião de articulação com a Associação Música Educação, Cultura e Esporte de Porto Seguro.
} 
No polo do trabalho prescrito está o saber constituído, o saber formalizado nos planos de ensino, nas normas técnicas, organizacionais, nos softwares, nas atribuições do cargo, etc., ou seja, são os conhecimentos sistematizados utilizados para orientar de modo generalizável a atividade do trabalho (TRINQUET, 2010). Esse saber foi explorado no momento da "capacitação" orientado pela pesquisa sobre as atribuições profissionais, a cultura e a história de cada público participante buscando promover o diálogo interno através da dialética entre o saber investido invocado no momento de sensibilização/acolhimento e o saber constituído das atribuições profissionais, ampliando espaços para novas estratégias de atuação. De acordo com Schwartz (2010, p.190):

É verdade que, no trabalho, há sempre uma espécie de destino a se viver. Não há outro jeito, sempre é necessário fazer escolhas. Se fazemos escolhas, por um lado elas são um risco, já que é preciso suprir os "vazios das normas", as deficiências de orientações, de conselhos, de experiências adquiridas, registradas nas regras ou nos procedimentos. Portanto: sim corremos riscos. Antecipamos soluções possíveis sabendo que efetivamente há o risco de falhar, de criar dificuldades novas, de desagradar...E, ao mesmo tempo, escolhe-se a si mesmo. [...] Cada pessoa vai "lidar com" as lacunas ou as deficiências a seu modo, pois ela não pode fazê-lo de maneira padronizada. Ela o faz com sua própria história, seus próprios valores.

O momento de "capacitação" foi orientado pela pesquisa sobre as atribuições profissionais, a cultura e a história de cada público participante, sendo assim, a sequência didática e sequência de conteúdo se organizaram segundo o público-participante. As oficinas realizadas nas comunidades cigana ${ }^{26} \mathrm{e}$ indígena foram direcionadas pelo diálogo entre a tradição e o acesso aos direitos sociais.

$\mathrm{Na}$ oficina com as organizações sociais, falamos sobre a educação entre pares e o fortalecimento institucional. Com os agentes de segurança pública como polícia militar e guarda municipal foi aprofundado o tema do racismo institucional e construção dos

\footnotetext{
${ }^{26}$ A oficina foi realizada na primeira escola cigana na Bahia. As meninas estudam até os 12 anos, algumas famílias deixam até os 14 ou 16. Os meninos saem da escola "devido o preconceito, se desmotivam e para casar também". As meninas não podem andar na rua sozinha, sempre acompanhada. Antigamente a menina já era prometida ao casamento na barriga da mãe, hoje perguntam para se eles querem casar. As meninas, que antes casavam a partir dos 12 anos, hoje casam a partir dos 15, 16 e os meninos a partir de 18, 19. Quando casam ambos entram para a vida adulta. Os pais das meninas são responsáveis por organizar o casamento e todo o enxoval da casa, os maridos tem a responsabilidade de sustentar a família.
} 
estereótipos criminais. Com agentes de proteção da Vara da Infância, Conselho Tutelar, agentes comunitários de saúde e refletimos sobre as atribuições profissionais e sua relação com as normas sociais construídas em espaços periféricos, local em que estes atores se encontram em atuação a maior parte do tempo laboral27.

Na oficina realizada com o MST, discutimos a sistematização dos saberes produzidos na escola do assentamento ${ }^{28}$ e o processo de construção de saberes para a valorização da infância "sem-terrinha". Finalizávamos as oficinas falando da importância de se atuar de forma positiva na rede de referência da criança e do adolescente, problematizando as estruturas sociais desiguais e refletindo sobre estratégias de atuação para a construção de um novo universo de escolhas e vidas possíveis em novas bases de sociabilidade.

\section{APONTAMENTOS FINAIS}

O campo social, talvez seja exatamente o lugar propício para o surgimento de novas estratégias e tecnologias sociais necessárias para se repensar as velhas mazelas sociais do Brasil. Também um passo para a escuta dos reais desafios que crianças e adolescentes enfrentam para fazerem da educação um caminho de sucesso e ter a sua pluralidade promovida.

Assim, diante das experiências aqui expostas, pode-se sinalizar para uma intervenção efetiva, agregadora e qualificada sobre as relações de infância e trabalho, a necessidade de uma aproximação desprovida de pré-julgamentos, crenças e valores arraigados. Requer despir-se de suas vestes para então vestir o lugar do outro e ser capaz

\footnotetext{
${ }_{27}$ "[...] um padrão de comportamento tal que as pessoas têm uma preferência para seguir esse padrão quando acreditam que muitas das pessoas de sua rede de referência comportam-se desse jeito, muitas pessoas da sua rede de referência acham que pessoas como elas deveriam comportar-se desse jeito" BICHIERI (2013. p.1).

28 Ponto importante da oficina "Como é a infância rural dentro do Movimento dos Trabalhadores Rurais sem Terra?" As principais resposta foram: "a construção da infância é na perspectiva de usufruto da terra..."; "Na infância há uma valorização da luta, uma valorização do ser em toda a sua totalidade...”; "O movimento tem sempre esse cuidado com a infância. Quando pensa no acampamento, a primeira coisa que pensa é na escola. Ano passado teve o encontro nacional dos sem terrinha. Desde pequenininhos eles sabem o que querem. O futuro são eles. Se não cuidarmos deles quem vai cuidar?...”.
} 
de, diante das realidades apresentadas, sugerir medidas que somadas aos valores daquele contexto, visem à prevalência da dignidade, do cuidado, da preservação do lugar da infância, em sua diversidade.

As principais estratégias construídas no processo dialógico das oficinas foram: 1. Continuidade dos estudos e o uso de base epistemológica do Sul, que privilegie autores decoloniais e a ecologia de saberes na produção acadêmica dos professores; 2. Construção de relatos de experiências que valorizem a infância dos sem-terrinhas, ampliando a discussão sobre as pluralidades de infâncias; 3. Divulgação em eventos científicos sobre a importância da agroecologia para a infância no MST, como forma de diminuição dos preconceitos e criminalizações que envolvem a atuação dos movimentos sociais no país; 4. Enfrentamento do racismo institucional a partir de um novo olhar que leve em conta o reconhecimento das pluralidades de infâncias em suas mais diversas situações de desigualdades sociais e/ou diversidades culturais; 5. Atividades preventivas/informativas em espaços escolares ou comunitários com foco no compartilhamento das histórias de vida dos próprios policiais, com a finalidade de se motivar as crianças e adolescentes a superarem suas dificuldades, permanecerem na escola e a optarem pelo caminho da educação; 6. Atuação positiva, não-violenta, em situações que não requeiram o uso legítimo da força física; 7. Capacitação continuada para compreender aspectos sociais, culturais, psicológicos, biológicos da criança e do adolescente, ou seja, aprender mais para atuar melhor; 8. Ouvir com sensibilidade, compreender o outro, não desistir de ninguém, tratar com humanidade ajuda no entendimento das razões dos conflitos, acolher e não rejeitar; 9. Atuação positiva, não-violenta, sendo flexível aos contextos, mediar conflitos, oferecer informações que possam ajudar em novas escolhas/oportunizar outros caminhos; 10. Criar um catálogo de recursos comunitários para melhor visualização dos parceiros no território (como OSC, associações de moradores e instituições religiosas) que atuem com atendimentos e/ou projetos sociais, educacionais ou culturais; 11. Buscar parcerias institucionais com Faculdades e Universidades para a sistematização de dados e construção da memória institucional do Conselho Tutelar no Município, apresentar resultados e relatos de experiências em eventos acadêmicos, atuar de forma preventiva 
através da produção de materiais informativos; 12. Intercâmbio e capacitação em gerenciamento de projetos e captação de recursos das organizações sociais no território como forma de fortalecer e ampliar a ação, principalmente em locais periféricos; 13. Eventos de valorização de cultura cigana em âmbito público e comunitário, utilizando equipamentos como o Centro de Cultura Municipal; 14. Atividades em âmbito escolar para discutir relações étnico-raciais, com foco na valorização da cultura negra, indígena e cigana; 15. Fortalecimento institucional da escola cigana através de parcerias com instituições públicas, privadas e educacionais para atuar junto ao acesso à educação e direitos das mulheres ciganas 29.

O Projeto atingiu seus objetivos oportunizando espaço de escuta e trocas de experiências entre os atores da rede de proteção da criança e do adolescente, oportunizando a abertura de um espaço participativo para construção de alternativas de atuação, pautados na proteção e promoção dos sujeitos envolvidos no fenômeno em questão. As novas alternativas de atuação se configuram como possibilidades concretas de se ampliar a efetividade das ações protetivas, a partir dos saberes advindos da própria experiência dos atores envolvidos (que envolve diferentes valorações sobre sua própria experiência com o trabalho na fase infanto-juvenil), de forma a impactar nas bases estruturais do fenômeno, levando-se em conta os múltiplos saberes existentes no espaço social, agregando-os como conhecimentos integradores para a proteção e promoção das múltiplas infâncias.

\section{REFERÊNCIAS}

${ }^{29}$ As alternativas de atuação do Projeto Infância e Trabalho foram publicadas em ARAÚJO, D.F.M.S; RIBEIRO, D.C; SILVA; P.G. O incentivo ao ergoengajamento dos atores sociais da rede de proteção da infância e do adolescente de Porto Seguro- BA: um relato de experiência do terceiro setor. Revista Encantar.

I Simpósio Latino-Americano de Ergologia. V.1, n.3, 2019. Disponível em: http://www.revistas.uneb.br/index.php/encantar/article/view/8465 Acesso: 20 ago. 2020. 
ALVES-MAZZOTI, Alda Judith. Repensando algumas questões sobre o trabalho infanto-juvenil. Revista Brasileira de Educação. n 9. Jan/Fev/Mar/Abr. 2002.

ARAÚJO, D. F. M. S. Espaços participativos: uma experiência de educação cidadã. Revista Focando a Extensão. v.10. n.7. 2017. Disponível:

https://periodicos.uesc.br/index.php/extensao/article/view/1903 Acesso: 22 dez. 2019.

ARAÚJO, D. F. M. S.; FELBERG,

A. Pluralidades e Subjetividades na Relação Infância e Trabalho: um olhar sobre a perspectiva indígena pataxó. Anais do $43^{\circ}$ Encontro Anual da ANPOCS, de 21 a 25 de outubro de 2019, em Caxambu-MG. ISSN 2177-3092. Disponível em: $<$ https://anpocs.com/index.php/encontros/papers/43-encontro-anual-da-anpocs/st11/st16-8/11727-pluralidades-e-subjetividades-na-relacao-infancia-e-trabalho-umolhar-sobre-a-perspectiva-indigena-pataxo Acesso: 20 ago. 2020.

ARAÚJO, D.F.M.S; RIBEIRO, D.C; SILVA; P.G. O incentivo ao ergoengajamento dos atores sociais da rede de proteção da infância e do adolescente de Porto Seguro- BA: um relato de experiência do terceiro setor. Revista Encantar. I Simpósio Latino-Americano de Ergologia. V.1, n.3, 2019. Disponível em: http://www.revistas.uneb.br/index.php/encantar/article/view/8465 Acesso: 20 ago. 2020.

ARAÚJO, D. F. M. S. Infâncias plurais: um olhar para o trabalho infanto-juvenil à luz da teoria da complexidade. Dissertação (Mestrado em Estado e Sociedade) - Programa de Pós-graduação em Estado e Sociedade da Universidade Federal do Sul da Bahia. Porto Seguro. p. 119. 2019.

ARAÚJO, F.M.B; ALVES, E.M; CRUZ, M.P. Algumas reflexões em torno dos conceitos de campo e de habitus a obra de Pierre Bourdieu. Revista Perspectivas da Ciência e Tecnologia. v.1, n. 1, jan-jun, 2009.

BERGER, Peter; LUCKMANN, Thomas. A construção social da realidade: tratado de sociologia do conhecimento. Petrópolis: Vozes. 1985.

BICHIERI, Cristina. Norms, conventions and the power of expectations. To appear in Philosophy of Social Science, N.Cartwright and E. Montuschi, eds., Oxford University Press. Fev 2013. Disponível: Acesso em: 07 jul. 2019.

BONDÍA. Carlos Larrosa. Notas sobre a experiência e o saber de experiência. Trad. João Wanderley Geraldi. Revista Brasileira de Educação. Jan/Fev/Mar/Abr. 2002.

BOURDIEU, Pierre. O poder simbólico. Tradução: Fernando Tomaz, $12^{\mathrm{a}}$ ed. Rio de Janeiro: Bertrand Brasil, 2009. 
A miséria do mundo. org. Pierre Bourdieu. 9. ed. Petrópolis,

RJ: Vozes. 2012.

CARVALHO, I. M. M. de. O trabalho infantil no Brasil contemporâneo. Caderno CRH, v. 21, n. 54, p. 551-569, 2008.

CARVALHO, Carlos Henrique de; MOURA, Esmeralda Blanco Bolsonaro de; ARAÚJO, José Carlos Sousa. A infância na modernidade: entre a educação e o trabalho. Uberlândia: EDUFU. 2007.

COOL, César. SOLÉ, Isabel. Os professores e a concepção construtivista. In: COOL, César. MARTÍN, Helena. MAURI, Teresa. MIRAS, Mariana. ONRUBIA, Javier. SOLÉ, Izabel. ZABALA, Antoni. O construtivismo na sala de aula. São Paulo: Ática, 1996.

CRUZ, Maria N. A; ASSUNÇÃO, Ada. A estrutura e organização do trabalho infantil em situação de rua em Belo Horizonte, MG, Brasil. Revista Saúde Sociedade. São Paulo. v.17. n.1.2008.

CUSSIANOVICH A. Tipología del trabajo infantil desde el punto de vista de los derechos humanos: la necesidad de una diferenciación [Versión electrónica]. En NATS Revista internacional desde los niños y adolescentes trabajadores. Año VII, $\mathrm{n}^{\mathrm{o}} \mathbf{1 1}^{-}$ 12, pp. 77-97. 2004.

DREYFUS, Hubert L. RABINOW, Paul. Michel Foucalult: más allá del estrueturalismo y la hemenéutica. $1^{\mathrm{a}}$ ed. - Buenos Aires: Ediciones Nueva Visión, 2001.

DUSSEL. Enrique. A colonialidade do saber: eurocentrismo e ciências sociais. Perspectivas latino-americanas. CLACSO, Consejo Latinoamericano de Ciencias Sociales. 2005.

FERREIRA, A. B. de H. Dicionário do Aurélio on-line. Disponível em: www.dicionariodoaurelio.com. Acesso em: 05 de jul.2019.

FREIRE, Paulo. Pedagogia da Autonomia: saberes necessários à prática educativa. 36ª edição. São Paulo: Paz e Terra, 1996.

GIANNELLA, Valéria. Espaço aberto para trocas: uma oficina sobre os paradoxos da mobilização social em contextos de exclusão extrema. Coleção Roteiros Gestão Social, v.1. Salvador: CIAGS/UFBA, 2009.

LACAN, Jacques. O Seminário, Livro 9: A identificação. Recife, Centro de Estudos Freudianos do Recife, 2003. 
LORDELO, Lia R; CHAVES, A. M. Crianças e adolescentes trabalhadores: uma revisão de literatura. Revista Entre Ideias, Salvador, n. 01, p. 61-83, jan./jun. 2012.

MARTINEZ, Albertina Mitjáns. Trabajo infantil y subjetividad: una perspectiva necessária. Revista Estudos de Psicologia. v. 6. n. 2. 2001.

MONTAGNER, Miguel A; MONTAGNER, Maria I. A teoria geral dos campos de Pierre Bourdieu: uma leitura. Revista Tempus Actas de Saúde Coletiva. v. 5. n. 2. 2011.

MONTANDON, C. Sociologia da infância: balanço dos trabalhos em língua inglesa. Cadernos de Pesquisa, São Paulo, v. 112, p. 33-6o, 2001.

MORIN, Edgar. Ciência com consciência. $11^{\mathrm{a}}$ ed. Rio de janeiro: Bertrand Brasil. 2008. . A religação de saberes. Rio de Janeiro: Bertrand Brasil. 2013.

SANTOS, Boaventura de Sousa. Por uma concepção multicultural de direitos humanos. Revista Crítica de Ciências Sociais. Nº48. Junho. 1997.

SCHWARTZ, Y. Uso de si e competência. In: SCHWARTZ, Y.; DURRIVE, L. (Org.). Trabalho \& Ergologia: conversas sobre a atividade humana. 2. ed. Niterói: EdUFF, 2010.

SCHWARTZ, Y.; DUC, M.; DURRIVE, L. A linguagem em trabalho. In: SCHWARTZ, Y.; DURRIVE, L. (Org.). Trabalho \& Ergologia: conversas sobre a atividade humana. 2. ed. Niterói: EdUFF, 2010.

SCLAVI, Marianella Arte di ascoltare e mondi possibili. Milão: Ristampa Bruno Mondadori, 2003.

SILVA, M. R. da. Recortando e colando imagens da vida cotidiana do trabalho e da cultura lúdica das meninas-mulheres e das mulheres meninas da zona da mata canavieira pernambucana. Cadernos CEDES, v. 22, n. 56, p. 23-52, 2002.

SIROTA, R. Emergência de uma sociologia da infância: evolução do objeto e do olhar. Cadernos de Pesquisa, São Paulo, v. 112, p. 7-31, 2001.

SOUZA, Jessé. A ralé brasileira: Quem é e como vive. Belo Horizonte: Editora UFMG. 2009.

TRINQUET, P. Trabalho e Educação: o método ergológico. Revista HISTEDBR, Campinas, v. 10, n. número especial, p. 93-113, ago. 2010. 
VILANI, Jane Araújo dos Santos. O que é trabalho infantil. São Paulo: Brasiliense. 2010.

WHITAKER, D. P. Nas franjas do rural-urbano: meninas entre a tradição e a modernidade. Cadernos CEDES, ano 22, n. 56, p. 7-22, abr. 2002.

ZABALA, Antoni. As sequências didáticas e as sequências de conteúdo. In: A Prática Educativa: Como Ensinar. Tradução de Ernani F. da Rosa. Porto Alegre: Artmed, 1998.

Sobre os autores

\section{Danielle Ferreira Medeiro da Silva de Araújo}

Doutoranda em Estado e Sociedade pelo Programa de Pós-Graduação da Universidade Federal do Sul da Bahia (UFSB). Especialista em Gênero, Sexualidade e Direitos Humanos pela ENSP/FIOCRUZ. Formada em Direito pela PUC/RJ. Docente na Faculdade Pitágoras e Nossa Senhora de Lourdes. Membra do Grupo de Pesquisa Paidéia - Laboratório de Pesquisa Transdisciplinar sobre Metodologias Integrativas para a Educação e Gestão Social. E-mail: dannymedeiro@hotmail.com.

\section{Débora Caraúna da Motta Ribeiro}

Especialista em Avaliação Psicológica pelo IPOG. Formação na Abordagem Centrada na Pessoa pelo Instituto Diabases da BA. Formada em Psicologia pela Faculdade Castro Alves. E-mail: caraúna_motta@hotmail.com

\section{Pétala Grecov Silva}

Discente em Pedagogia pela Faculdade Nossa Senhora de Lourdes (FNSL). E-mail: petalagrecov@gmail.com

\section{Altemar Felberg}

Doutorando em Estado e Sociedade pelo Centro de Formação em Ciências Humanas e Sociais (CFCHS) da Universidade Federal do Sul da Bahia (UFSB). Mestre em Ciências da Educação (ULHT, Lisboa). Especialista em Estudos Transdisciplinares em Cultura (UNEB); Especialista em Gestão Pública (UNEB); Especialista em Educação, 
Desenvolvimento e Políticas Educativas (CINTEP/FNSL). Graduado em Administração com Habilitação em Marketing (FACDESCO). Membro do Grupo de Pesquisa Paidéia Laboratório de Pesquisa Transdisciplinar sobre Metodologias Integrativas para a Educação e Gestão Social. Integrante de Projeto de Pesquisa "Perspectivas e desafios da participação em tempos de crise democrática” (CFCHS/UFSB). 